\title{
Changes in Lipid Profile Between Flare and Remission of Patients with Systemic Lupus Erythematosus: A Prospective Study
}

\author{
MARIA URQUIZU-PADILLA, EVA BALADA, PILAR CHACON, EDUARDO HERMOSILLA PÉREZ, \\ MIQUEL VILARDELL-TARRÉS, and JOSEP ORDI-ROS
}

\begin{abstract}
Objective. To determine the lipid profile of patients with systemic lupus erythematosus (SLE) according to the disease activity, and to calculate the percentage of patients that diverged from optimal values.

Methods. Serum was collected from 52 patients with SLE at flare and at remission. SLE disease activity was measured by using the SLE Disease Activity Index (SLEDAI). Clinical and biological measures were evaluated in both situations. Total cholesterol (TC), high-density lipoprotein cholesterol (HDLC), low-density lipoprotein cholesterol (LDLC), and triglyceride (TG) levels were analyzed after overnight fasting. We also calculated the atherogenic ratios of TC/HDLC and LDLC/HDLC.

Results. SLE patients had significantly higher median TC/HDLC and LDLC/HDLC ratios at flare than during remission: $4.5 \pm 1.5$ versus $3.9 \pm 1.0(\mathrm{p}=0.007)$ and $2.7 \pm 1.1$ versus $2.4 \pm 0.8(\mathrm{p}=$ $0.015)$, respectively. The differences persisted after adjustments based on kidney disease and treatment but not after adjusting by creatinine clearance $<60 \mathrm{ml} / \mathrm{min} / 1.73 \mathrm{~m}^{2}$ in remission. The variation between flare and remission of the percentage of SLE patients with high-risk levels of lipid profile to desirable values, and vice versa, was statistically significant for the LDLC/HDLC ratio (9 vs 1; $\mathrm{p}=0.021$ ).

Conclusion. Our results reflect a higher risk of atherosclerosis phenomena in SLE patients during flare than during clinical remission. This might explain the propensity to develop coronary heart disease in patients with SLE. (First Release June 15 2009; J Rheumatol 2009;36:1639-45; doi:10.3899/ jrheum.081097)
\end{abstract}

\section{Key Indexing Terms: \\ SYSTEMIC LUPUS ERYTHEMATOSUS BIOLOGICAL MARKERS}

DISEASE ACTIVITY

\section{ARTERIOSCLEROSIS CHOLESTEROL}

Systemic lupus erythematosus (SLE) is an autoimmune disease of unknown etiology. Premature coronary heart disease (CHD) has emerged as a major cause of morbidity and mortality in patients with $\mathrm{SLE}^{1,2}$. Young women with SLE have an estimated 50-fold increased risk of myocardial infarction compared with age and sex-matched controls ${ }^{1}$. The major cause of CHD in these patients is premature atherosclerosis disease ${ }^{3}$.

A small number of studies have attempted to identify the

From the Systemic Autoimmune Diseases Research Laboratory, Vall d'Hebron Research Institute, Vall d'Hebron Hospital, Barcelona, Spain.

Dr. Urquizu-Padilla was supported by funds provided by the Spanish Ministerio de Sanidad y Consumo via the Instituto de Salud Carlos III (CM04/00034).

M. Urquizu-Padilla, MD, PhD; E. Balada, PhD; P. Chacon, MD, PhD; E. Hermosilla Pérez; M. Vilardell-Tarrés, $M D, P h D$, Professor:

J. Ordi-Ros, MD, PhD, Systemic Autoimmune Diseases Research Laboratory.

Address correspondence to Dr. M. Urquizu-Padilla, Research Unit in Systemic Autoimmune Diseases, Vall d'Hebron Research Institute, Hospital Vall d'Hebron, Passeig Vall d'Hebron 119-129, 08035

Barcelona, Spain.E-mail: mariaurquizu@gmail.com

Accepted for publication March 9, 2009. risk factors for CHD in SLE by comparing patients who have SLE and documented CHD with SLE patients who do not develop $\mathrm{CHD}^{1,4,5}$. Elevated concentrations of total cholesterol (TC) were consistently identified by all the studies as a risk factor, and it may be responsible for the atherosclerosis process in these patients.

The dyslipoproteinemia observed in patients with SLE has a multifactor origin. It is complex to elucidate which factors are clearly involved in the pathophysiology of this lipid disorder. Among these factors, drugs (particularly steroids at high dose $e^{6-8}$ ), renal involvement ${ }^{7}$, and disease activity ${ }^{9}$ seem to have a leading role.

To our knowledge, no study in the literature in adult lupus has focused on the lipid profile in the same patient during flare and in remission to evaluate the effect of the disease activity. Sarkissian, et al ${ }^{10,11}$ published 2 reports of a retrospective study in pediatric lupus describing lipid profiles of an inception cohort, and evaluating the factors that could modify it using complex statistical analysis.

We believe this is the first prospective study assessing the variations in the lipid profile between flare and remission in Personal non-commercial use only. The Journal of Rheumatology Copyright (C) 2009. All rights reserved. 
a cohort of patients with SLE; we also addressed the relationship with variables linked to SLE.

\section{MATERIALS AND METHODS}

Data were collected from 52 consecutive individuals with SLE who had had a flare of SLE and who later had a remission. All patients fulfilled at least 4 American College of Rheumatology revised criteria for the classification of SLE ${ }^{12}$. SLE activity was assessed by the SLE Disease Activity Index (SLEDAI) $)^{13}$.

A flare was defined as any clinical event directly attributable to disease activity that required a change in treatment and that showed a SLEDAI result $\geq 6$. At the time of flare, a blood sample was taken and sent to the laboratory.

All patients who gave a blood sample during flare were followed periodically in order to detect remission. When clinical remission was detected, another blood sample was taken and analyzed. We considered the patient was in remission if the SLEDAI was $\leq 6$ and when this result meant a $50 \%$ decrease from the SLEDAI flare score.

The patient's history was reviewed: demographic and SLE-related data were collected [disease status, atherosclerotic risk factors (Paffenbarger Physical Activity Questionnaire ${ }^{14}$ was used to measure the expenditure of $\mathrm{kcal} /$ week; we estimated the 10 -year global risk of CHD with the Regicor ${ }^{15}$ and Dorica ${ }^{16}$ scales, which are adaptations of the Framingham scale according to the prevalence of independent risk factors and incidence of coronary events in Catalan and Spanish populations, respectively), laboratory findings, type of clinical symptoms at flare and during remission, and the treatment at the time of blood sampling and to treat the flare].

Subjects' written consent was obtained according to the Declaration of Helsinki, and the study design conformed to standards currently applied in Spain $^{17}$

Sample collection. Samples were extracted after overnight fasting. Whole blood was collected into plain tubes. Lipid analyses were all carried out on unfrozen samples. Total serum cholesterol (TC) and total triglycerides (TG) were tested by an automated colorimetric enzymatic method (Tokio 192-8512, Tokyo, Japan) on an Olympus AU-5400 analyzer (Olympus, Tokyo, Japan). Serum high-density lipoprotein cholesterol (HDLC) was determined by an automated colorimetric enzymatic method with antibodies against apolipoprotein B (apo B; Tokio 192-8512) on an Olympus AU-5400 analyzer. Low-density lipoprotein cholesterol (LDLC) was calculated following Friedewald's equation [LDLC $=\mathrm{TC}-\mathrm{HDLC}-(\mathrm{TG} / 5)$ ] when the serum TG level was $<2.82 \mathrm{mmol} / \mathrm{l}$. When TG values were $>2.82$ mmol/l, LDLC was determined by sequential ultracentrifugation ${ }^{18}$. The serum was adjusted to a density of $1.006 \mathrm{~g} / \mathrm{ml}$ with sodium bromide solution and ultracentrifuged at $40,000 \mathrm{rpm}$ for $21 \mathrm{~h}$ at $15^{\circ} \mathrm{C}$ in a Beckman L8-M rotor-type TFT 45.6. After centrifugation, the very-low-density lipoprotein cholesterol (VLDLC) was carefully removed and LDLC concentration was calculated as: LDLC $=\mathrm{TC}-\mathrm{HDLC}-\mathrm{VLDLC}$. In addition, LDLC was corrected by subtracting the cholesterol portion of lipoprotein(a), estimated as $0.3 \times$ lipoprotein(a) concentration ${ }^{19}$.

Lipid profile levels of risk for coronary heart disease. The lipoprotein level of risk was determined based on the updated recommendations of the National Cholesterol Education Program (NCEP) ${ }^{20}$. The NCEP guidelines suggest a desirable total cholesterol level $<5.17 \mathrm{mmol} / \mathrm{l}$ and define low HDLC when $<1.03 \mathrm{mmol} / \mathrm{l}$. Desirable levels of LDLC and TG were defined as $<3.36 \mathrm{mmol} / \mathrm{l}$ and $<1.64 \mathrm{mmol} / \mathrm{l}$, respectively. For the atherogenic ratios, we applied those proposed by the investigators of the Framingham study ${ }^{21}$ : TC/HDLC ratio $\leq 5$ in men and $\leq 4.5$ in women; and LDLC/HDLC ratio $\leq 3.5$ in men and $\leq 3$ in women.

Statistical analysis. Continuous variables were expressed as means \pm standard deviation (SD) or medians [interquartile range (IQR)] if data were skewed; categorical variables were expressed as numbers and percentages.

To evaluate differences in the categorical variables between the 2 disease stages (flare and remission) we used the McNemar test. To evaluate continuous variables in the 2 disease stages we used the paired-sample T test for variables that followed a normal distribution and the Wilcoxon matched-pairs signed-rank test for variables that did not.

Since some drugs (especially high doses of prednisone) and kidney disease seem to alter the lipid profile, we constructed a general linear model for repeated measures to evaluate the changes between flare and remission for those significant variables, entering each of the following variables, as between-subjects factor (if categorical)/covariate (if continuous): renal flare, clearance of creatinine during remission $<60 \mathrm{ml} / \mathrm{min} / 1.73 \mathrm{~m}^{2}$, prednisone dose in flare $>10 \mathrm{mg} / \mathrm{day}$, accumulated dose of prednisone $(\mathrm{mg})$ until flare, treatment with antimalarials (at flare and at remission), and cyclosporine/tacrolimus and mycophenolate/azathioprine therapy during remission.

Mann-Whitney U test (for non-normal variables) or the independent samples $t$ test (normal variables) for equality of means (along with Levene's test for equality of variances) was used to compare means between nonpaired groups. Relationships between 2 continuous variables were examined by Pearson's correlation coefficient (r) if both variables had normal distribution; otherwise, Spearman's rank correlation coefficient $\left(\mathrm{r}_{\mathrm{s}}\right)$ was used.

$\mathrm{p}$ values $(2$-tailed $)<0.05$ were considered statistically significant. All analyses were performed with the Statistical Package for Social Sciences (SPSS, Chicago, IL, USA), version 12.0.

\section{RESULTS}

Our patients were mainly female $(\mathrm{n}=46 ; 88.5 \%)$ and Caucasian (45; 86.5\%); other ethnic groups included 5 Latin American, 1 Gypsy, and 1 Arab. The median age was $31.1 \pm$ 12.4 years. There were $9(17.3 \%)$ obese patients (body mass index $\geq 30$ ) and 13 patients $(25 \%)$ had a sedentary lifestyle $(<2000 \mathrm{kcal} /$ week). Other variables related to atherosclerosis, disease status, type of clinical symptomatology, and treatment are detailed in Table 1. No patient was diabetic and no patient had a history of either CHD or ictus.

Influence of disease activity on lipid profile. SLE patients had significantly higher mean levels of both atherogenic ratios during flare than during remission: TC/HDLC ratio $4.5 \pm 1.5$ versus $3.9 \pm 1.0(\mathrm{p}=0.007)$ and LDLC/HDLC ratio $2.7 \pm 1.1$ versus $2.4 \pm 0.8(\mathrm{p}=0.015)$. We found no significant differences between values during flare and during remission for TC, HDLC, LDLC, and TG (Table 2). Nevertheless, a tendency to a worse lipid profile was observed at flare. After excluding menopausal women from the analysis, we observed the same result: TC/HDLC ratio $4.6 \pm 1.5$ versus $4.0 \pm 1.1(\mathrm{p}=0.005)$ and LDLC/HDLC ratio $(2.7 \pm 1.1$ versus $2.4 \pm 0.8(\mathrm{p}=0.015)$, without finding significant differences between values during flare and during remission for the other lipid profile variables.

When we applied a general linear model for repeated measures, we found that the changes between flare and remission in the TC/HDLC and LDLC/HDLC ratios retained statistical significance after adjusting for the effect of renal flare $(\mathrm{p}=0.009$ and $\mathrm{p}=0.003$, respectively), prednisone dose during flare $>10 \mathrm{mg} /$ day $(\mathrm{p}=0.005$ and $\mathrm{p}=$ $0.024)$, accumulated dose of prednisone until flare $(\mathrm{p}=$ 0.046 and $p=0.023$ ), use of antimalarial drugs during flare $(\mathrm{p}=0.007$ and $\mathrm{p}=0.017)$ or remission $(\mathrm{p}=0.007$ and $\mathrm{p}=$ 0.023 ), cyclosporine/tacrolimus treatment during remission 
Table 1. Disease status variables, immunological and serological features, atherosclerosis-related variables, clinical symptomatology, and treatment received during flare and remission.

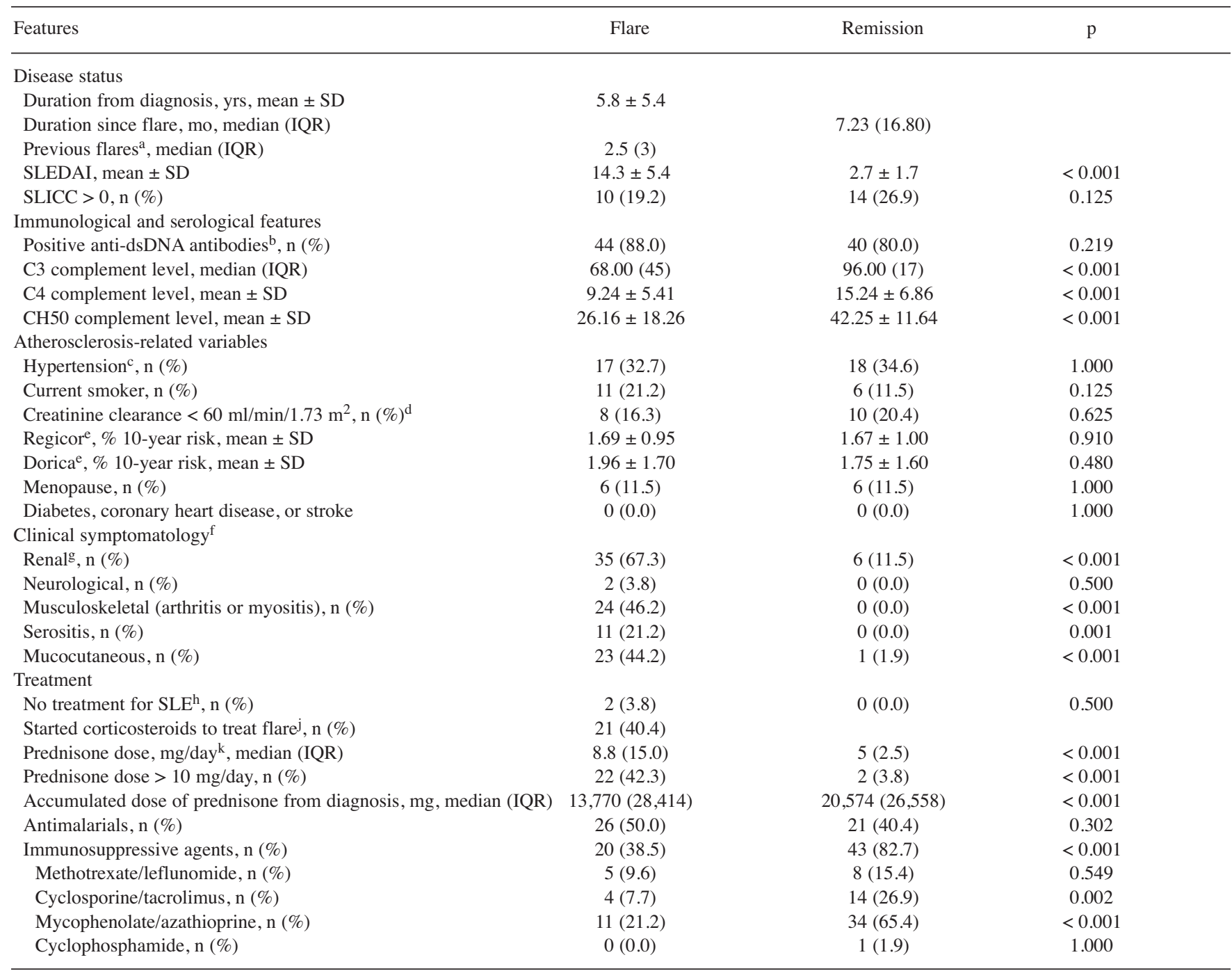

${ }^{a}$ Any flare (including current flare) with SLEDAI $\geq 6$ was considered. ${ }^{\mathrm{b}}$ Anti-double-stranded DNA antibodies above normal range for testing laboratory. c Systolic blood pressure $\geq 140$ and/or diastolic blood pressure $\geq 90 \mathrm{~mm} \mathrm{Hg} 3$ separate times and/or when patient was receiving antihypertensive drugs.

${ }^{d}$ Estimated with Modification of Diet in Renal Disease. ${ }^{e}$ Adaptations of the Framingham scale according to prevalence of independent risk factors and incidence of coronary events in Catalan and Spanish population, respectively, to estimate 10 -year global risk of coronary heart disease. Score $<5 \%$ confers low risk. ${ }^{\mathrm{f}}$ Disease activity events were restricted to those of SLEDAI scores. ${ }^{\mathrm{g}}$ Patients with proteinuria as new onset $(>0.5 \mathrm{~g} / 24 \mathrm{~h})$ or recent increase $>0.5 \mathrm{~g} / 24$ $\mathrm{h}$. During remission all proteinuria values were lower than flare but higher than recent previous measure; ${ }^{\mathrm{h}}$ At time of sampling patient was not taking immunosuppressive agents, corticosteroids, or antimalarials. ${ }^{\mathrm{j}}$ Blood sample was taken after modifying or introducing corticosteroid doses (we did not accept any patient with recent changes in immunosuppressive therapy). ${ }^{\mathrm{k}}$ Prednisone or equivalent (mg/day) at time of blood-sampling.

$(\mathrm{p}=0.010$ and $\mathrm{p}=0.031)$, and mycophenolate/azathioprine treatment during remission $(\mathrm{p}=0.006$ and $\mathrm{p}=0.024$, respectively). Adjusting by clearance in remission at $<60$ $\mathrm{ml} / \mathrm{min} / 1.73 \mathrm{~m}^{2}$ we found that the statistical significance disappeared. Thus, we analyzed changes in the TC/HDLC and LDLC/HDLC ratios between flare and remission in this group of patients with clearance in remission of $<60$ $\mathrm{ml} / \mathrm{min} / 1.73 \mathrm{~m}^{2}$, and observed no statistically significant differences $(4.7 \pm 1.0$ vs $4.9 \pm 1.0, p=0.236$; and $3.0 \pm 0.7$ vs $3.2 \pm 0.8, \mathrm{p}=0.270$, respectively). In the group of patients with clearance during remission $\geq 60 \mathrm{ml} / \mathrm{min} / 1.73$ $\mathrm{m}^{2}$, statistically significant differences were still observed $(4.9 \pm 1.7$ vs $3.7 \pm 0.9, \mathrm{p}=0.002$; and $2.7 \pm 1.2$ vs $2.2 \pm 0.7$, $\mathrm{p}=0.006$, respectively).

Lipid risk levels. We calculated the percentage of lipid profile values that diverged from optimal levels during flare and during remission (Table 3). Although the percentage of lipid profile values that diverged from optimal levels was higher during flare than during remission for all measures, none achieved statistical significance (data not shown). When we 
Table 2. Lipid profile: measures and differences between flare and remission.

\begin{tabular}{lccc}
\hline Lipid Profile & Flare & Remission & $\mathrm{p}$ \\
\hline Total cholesterol, mmol/l, mean \pm SD & $5.44 \pm 1.40$ & $5.15 \pm 1.08$ & 0.110 \\
HDLC, mmol/l, mean \pm SD & $1.33 \pm 0.49$ & $1.37 \pm 0.40$ & 0.491 \\
LDLC, mmol/l, mean \pm SD & $3.33 \pm 1.19$ & $3.13 \pm 0.84$ & 0.149 \\
Triglycerides, mmol/l, median (IQR) & $1.41(0.99)$ & $1.29(1.00)$ & 0.090 \\
TC/HDLC ratio, mean \pm SD & $4.5 \pm 1.5$ & $3.9 \pm 1.0$ & 0.007 \\
LDLC/HDLC ratio, mean \pm SD & $2.7 \pm 1.1$ & $2.4 \pm 0.8$ & 0.015 \\
\hline
\end{tabular}

HDLC: high-density lipoprotein cholesterol; LDLC: low-density lipoprotein cholesterol; TC: total cholesterol.

Table 3. Percentages of SLE patients in flare and remission that diverged from the desirable levels for each value of lipid profile, and percentage of patients changing high-risk levels during flare to desirable levels in remission, and vice versa. $p$ value compares these latter changes.

\begin{tabular}{lcccc}
\hline Lipid Profile & Flare & Remission & $\begin{array}{c}\text { Changing from Risky } \\
\text { to Desirable Levels }\end{array}$ & $\begin{array}{c}\text { Changing from } \\
\text { Desirable to Risky Levels }\end{array}$ \\
\hline Total cholesterol $\geq 5.17 \mathrm{mmol} / \mathrm{l}, \mathrm{n}(\%)$ & $28(53.8)$ & $24(46.2)$ & $8(15.4)$ & $4(7.7)$ \\
(McNemar)
\end{tabular}

$* \leq 5$ in men, $\leq 4.5$ in women. $* * \leq 3.5$ in men, $\leq 3$ in women. HDLC: high-density lipoprotein cholesterol; LDLC: low-density lipoprotein cholesterol; TC: total cholesterol.

analyzed the variation from risk levels during flare compared to optimal values during remission and vice versa, we found that LDLC/HDLC ratio had a statistically significant variation. Nine patients diverged from optimal values during flare and changed to optimal values in remission, and only 1 patient had optimal values during flare and changed to undesirable values during remission.

The same results, statistically significant changes of only the LDLC/HDLC ratio, were observed when we analyzed patients grouped according to clearance during remission $\geq$ $60 \mathrm{ml} / \mathrm{min} / 1.73 \mathrm{~m}^{2}$ and after excluding menopausal women $(\mathrm{p}=0.039$ in both analyses). However, when we analyzed only patients with clearance in remission $<60 \mathrm{ml} / \mathrm{min} / 1.73$ $\mathrm{m}^{2}$, there was no statistically significant change in any lipid profile variable.

During flare, 40 out of 52 patients (76.9\%) had at least one lipid profile value higher than optimal levels. During remission 37 of 52 patients $(71.2 \%)$ had at least one lipid profile value higher than optimal levels. Both percentages of at least one lipid profile value higher than the desirable levels were the same at flare and at remission $(\mathrm{p}=0.502)$.

Only 2 patients in our study were receiving statin therapy at flare; thus, it was not possible to analyze the specific effects of statins on lipids, and the effect of this medication was considered negligible.

Other analysis. We examined the association between lipid levels during flare and during remission and serological and immunological features. We found that levels of antidsDNA antibodies correlated with several levels of lipid values, during flare (HDLC $\mathrm{r}_{\mathrm{s}}=-0.395, \mathrm{p}=0.004$; TC/HDLC ratio $r_{s}=0.365, p=0.008 ;$ LDLC/HDLC ratio $r_{s}$ $=0.330, \mathrm{p}=0.022)$ and during remission $\left(\operatorname{HDLC} \mathrm{r}_{\mathrm{s}}=\right.$ $-0.307, \mathrm{p}=0.028 ;$ TC/HDLC ratio $\mathrm{r}_{\mathrm{s}}=0.280, \mathrm{p}=0.046$ ). Values of $\mathrm{C} 3$ correlated with several levels of lipid values during flare (HDLC $\mathrm{r}=0.308, \mathrm{p}=0.026$; triglycerides $\mathrm{r}_{\mathrm{s}}=$ $-0.341, \mathrm{p}=0.013$; TC/HDLC ratio $\mathrm{r}=-0.404, \mathrm{p}=0.003$; LDLC/HDLC ratio $r=-0.362, p=0.011)$ and the same outcome was found for CH50 (triglycerides $\mathrm{r}_{\mathrm{s}}=-0.317, \mathrm{p}=$ 0.034 ; TC/HDLC ratio $r=-0.352, p=0.018)$. Values of fibrinogen correlated negatively with both ratios only during remission (TC/HDLC ratio $\mathrm{r}=-0.305, \mathrm{p}=0.028$; LDLC $/$ HDLC ratio $r=-0.326, p=0.021)$.

\section{DISCUSSION}

SLE is associated with an increased risk of atherosclerosis. To our knowledge, our data are the first taking serial samples to analyze levels of lipid profiles from the same adult patient with SLE at 2 different periods of disease flare and remission. We believe this is the first such prospective study in SLE patients. Previously, Sarkissian, et al published 2 retrospective studies $^{10,11}$, limited to pediatric patients. Both described the same sample of patients, and differed in the way patients were grouped in the statistical methods and the conclusions achieved.

We observed no statistically significant differences between flare and remission in absolute values of the lipid profiles (although we observed a tendency to worsening of all the lipid profile values during flare compared with values Personal non-commercial use only. The Journal of Rheumatology Copyright (C) 2009. All rights reserved. 
during remission). Only TC/HDLC and LDLC/HDLC ratios were higher at flare than at remission. Therefore, according to previous studies ${ }^{9,10,22-27}$, the lipid profile worsened during flare. Indeed, we observed that several lipid profile values showed correlation with serological and immunological markers of disease activity.

Many studies have confirmed that TC/HDLC and LDLC/HDLC ratios are potent predictors of coronary risk, and this predictive power is maintained for any serum level of TC in both men and women of all ages, being a more powerful predictor of coronary risk than serum levels of TC, LDLC, or HDLC considered independently $28-32$

Data from large observational ${ }^{33-35}$ and angiographic studies suggest that the TC/HDLC ratio is a more powerful predictor of coronary risk than serum levels of TC, LDLC, or HDLC used independently, being a reliable discriminator of the presence and extent of CHD in women ${ }^{36-38}$. The TC/HDLC index has been considered by some investigators ${ }^{29}$ a better coronary risk predictor than LDLC/HDLC because the former includes all apoB-containing lipoproteins in the numerator and not only LDL. It has recently been described in a large metaanalysis ${ }^{39}$ that the TC/HDLC ratio is the strongest predictor of CHD. For the TC/HDLC ratio there were strong positive associations with CHD mortality at all ages, with no evidence of thresholds (within the range 3.7 to 7.0 ) beyond which higher TC/HDLC ratio was no longer associated with higher CHD mortality. Hence, a higher index implies an increased cardiovascular risk, and lowering this ratio has been shown to decrease this risk for example, lowering this ratio from 6.0 to 4.5 halves the 5 -year rate of coronary disease in women ${ }^{40}$. Therefore, we may assume that our patients with higher values of TC/HDLC ratio during flare than during remission had increased cardiovascular risk during flare.

A study is needed to determine a possible association between LDLC/HDLC ratio and mortality due to CHD. Consequently, despite the higher values during flare than during remission, we cannot conclude that this increase would mean an increase of CHD risk. However, we found that there were a statistically significant number of patients with a pathological LDLC/HDLC ratio during flare that changed to desirable values during remission, compared to the other way around. Consequently, we may assume that our patients with pathological HDLC/LDLC ratios during flare that changed to desirable values in remission had increased cardiovascular risk during flare.

The same phenomenon described in our survey with regard to lipid values has been observed in patients with early rheumatoid arthritis (another disease associated with excess cardiovascular morbidity and mortality). In a study in the same patients (under treatment and after achieving response criteria), a significant reduction was observed of the atherogenic TC/HDLC ratio $^{41}$ and the LDLC/HDLC ratio $^{41}$. However, in SLE these ratios, representing athero- genic indexes of important prognostic markers for cardiovascular disease, have been underevaluated ${ }^{7,10,22,26,42}$. Blood levels of TC and other lipid fractions have been used widely to predict CHD in patients with SLE, but there are few studies evaluating the ratios in such patients $7,43,44$.

We chose to evaluate the influence of renal flare $7,10,42,45$, creatinine clearance ${ }^{46}$, prednisone doses ${ }^{3,6-8,10,11,25,44,47-49}$, and antimalarial treatment ${ }^{47,50}$ on the change of values of the 2 ratios during flare and during remission because previous studies have shown that these variables are related to lipid profile in SLE. Since we observed a higher percentage of patients receiving immunosuppressive agents during remission, we also evaluated the influence of their use on the change of both ratios during flare and remission. The study revealed that changes in levels of ratios were mainly associated with changes in disease activity. The significant changes of both ratios between flare and remission that we found were influenced only by a clearance of creatinine in remission of less than $60 \mathrm{ml} / \mathrm{min} / 1.73 \mathrm{~m}^{2}$. The ratios in these patients did not change between flare and remission, and there were no statistically significant changes in the percentage of patients that changed from undesirable values during flare to desirable values during remission, and vice versa. In these patients, renal disease was found to be the main influence on lipid profile, not changing in relation with disease activity. These findings are consistent with other studies showing the relation between nephropathy and lipid profile in SLE $^{7,10,42,45}$.

Considering the utility of the 2 lipid ratios in our study, we would recommended measurement of atherogenic ratios in all SLE patients to evaluate cardiovascular risk. Our results are in accord with accumulating evidence of the intriguing interactions among dyslipidemia, atherosclerosis, and inflammation, showing a worsening of the lipid profile during increased disease activity. Given the increasing recognition of coronary heart disease as an important morbidity and mortality outcome in patients with SLE, our data would support aggressive primary prevention of coronary heart disease based on treatment to avoid flares and to treat patients with an adverse lipid profile more intensively.

\section{ACKNOWLEDGMENT}

We thank Dr. Xavier Pintó for review of the manuscript.

\section{REFERENCES}

1. Manzi S, Meilahn EN, Rairie JE, et al. Age-specific incidence rates of myocardial infarction and angina in women with systemic lupus erythematosus: comparison with the Framingham Study. Am J Epidemiol 1997;145:408-15.

2. Ward MM. Premature morbidity from cardiovascular and cerebrovascular diseases in women with systemic lupus erythematosus. Arthritis Rheum 1999;42:338-46.

3. Bulkley BH, Roberts WC. The heart in systemic lupus erythematosus and the changes induced in it by corticosteroid therapy. A study of 36 necropsy patients. Am J Med 1975;58:243-64.

4. Gladman DD, Urowitz MB. Morbidity in systemic lupus Personal non-commercial use only. The Journal of Rheumatology Copyright @ 2009 . All rights reserved. 
erythematosus. J Rheumatol Suppl 1987;14 Suppl 13:223-6.

5. Petri M, Perez-Gutthann S, Spence D, Hochberg MC. Risk factors for coronary artery disease in patients with systemic lupus erythematosus. Am J Med 1992;93:513-9.

6. Maxwell SR, Moots RJ, Kendall MJ. Corticosteroids: do they damage the cardiovascular system? Postgrad Med J 1994;70:863-70.

7. Leong KH, Koh ET, Feng PH, Boey ML. Lipid profiles in patients with systemic lupus erythematosus. J Rheumatol 1994;21:1264-7.

8. Ettinger WH, Goldberg AP, Applebaum-Bowden D, Hazzard WR. Dyslipoproteinemia in systemic lupus erythematosus. Effect of corticosteroids. Am J Med 1987;83:503-8.

9. Ilowite NT, Samuel P, Ginzler E, Jacobson MS. Dyslipoproteinemia in pediatric systemic lupus erythematosus. Arthritis Rheum 1988;31:859-63.

10. Sarkissian T, Beyene J, Feldman B, McCrindle B, Silverman ED. Longitudinal examination of lipid profiles in pediatric systemic lupus erythematosus. Arthritis Rheum 2007;56:631-8.

11. Sarkissian T, Beyenne J, Feldman B, Adeli K, Silverman E. The complex nature of the interaction between disease activity and therapy on the lipid profile in patients with pediatric systemic lupus erythematosus. Arthritis Rheum 2006;54:1283-90.

12. Hochberg MC. Updating the American College of Rheumatology revised criteria for the classification of systemic lupus erythematosus [letter]. Arthritis Rheum 1997;40:1725.

13. Bombardier C, Gladman DD, Urowitz MB, Caron D, Chang CH Derivation of the SLEDAI. A disease activity index for lupus patients. The Committee on Prognosis Studies in SLE. Arthritis Rheum 1992;35:630-40.

14. Paffenbarger RS Jr, Hyde RT, Wing AL, Hsieh CC. Physical activity, all-cause mortality, and longevity of college alumni. N Engl J Med 1986;314:605-13.

15. Marrugat J, D'Agostino R, Sullivan L, et al. An adaptation of the Framingham coronary heart disease risk function to European Mediterranean areas. J Epidemiol Community Health 2003;57:634-8.

16. Aranceta J, Perez Rodrigo C, Foz Sala M, et al. Tables of coronary risk evaluation adapted to the Spanish population: the DORICA study. Med Clin (Barc) 2004;123:686-91.

17. Vollmann J, Winau R. Informed consent in human experimentation before the Nuremberg code. BMJ 1996;313:1445-9.

18. Havel RJ, Eder HA, Bragdon JH. The distribution and chemical composition of ultracentrifugally separated lipoproteins in human serum. J Clin Invest 1955;34:1345-53.

19. Seman LJ, Jenner JL, McNamara JR, Schaefer EJ. Quantification of lipoprotein(a) in plasma by assaying cholesterol in lectin-bound plasma fraction. Clin Chem 1994;40:400-3.

20. Third Report of the National Cholesterol Education Program (NCEP) Expert Panel on Detection, Evaluation, and Treatment of High Blood Cholesterol in Adults (Adult Treatment Panel III) final report. Circulation 2002;106:3143-421.

21. Gordon T, Kannel WB. Multiple risk functions for predicting coronary heart disease: the concept, accuracy, and application. Am Heart J 1982;103:1031-9.

22. Borba EF, Bonfa E. Dyslipoproteinemias in systemic lupus erythematosus: influence of disease, activity, and anticardiolipin antibodies. Lupus 1997;6:533-9.

23. Alverson DC, Chase HP. Systemic lupus erythematosus in childhood presenting as hyperlipoproteinemia. J Pediatr 1977;91:72-5.

24. Posadas-Romero C, Torres-Tamayo M, Zamora-Gonzalez J, et al High insulin levels and increased low-density lipoprotein oxidizability in pediatric patients with systemic lupus erythematosus. Arthritis Rheum 2004;50:160-5.

25. Pauciullo P, De Simone B, Rubba P, Mancini M. A case of association between type I hyperlipoproteinemia and systemic lupus erythematosus. Effects of steroid treatment. J Endocrinol Invest 1986;9:517-20.

26. Kashef S, Ghaedian MM, Rajaee A, Ghaderi A. Dyslipoproteinemia during the active course of systemic lupus erythematosus in association with anti-double-stranded DNA (anti-dsDNA) antibodies. Rheumatol Int 2007;27:235-41.

27. Svenungsson E, Gunnarsson I, Fei GZ, Lundberg IE, Klareskog L, Frostegard J. Elevated triglycerides and low levels of high-density lipoprotein as markers of disease activity in association with up-regulation of the tumor necrosis factor alpha/tumor necrosis factor receptor system in systemic lupus erythematosus. Arthritis Rheum 2003;48:2533-40.

28. Gotto AM Jr, Whitney E, Stein EA, et al. Relation between baseline and on-treatment lipid parameters and first acute major coronary events in the Air Force/Texas Coronary Atherosclerosis Prevention Study (AFCAPS/TexCAPS). Circulation 2000;101:477-84.

29. Kinosian B, Glick H, Garland G. Cholesterol and coronary heart disease: predicting risks by levels and ratios. Ann Intern Med 1994;121:641-7.

30. Stampfer MJ, Sacks FM, Salvini S, Willett WC, Hennekens CH. A prospective study of cholesterol, apolipoproteins, and the risk of myocardial infarction. N Engl J Med 1991;325:373-81.

31. Miller M, Seidler A, Kwiterovich PO, Pearson TA. Long-term predictors of subsequent cardiovascular events with coronary artery disease and 'desirable' levels of plasma total cholesterol. Circulation 1992;86:1165-70.

32. Swan HJ. The Framingham Offspring Study: a commentary. 1980. J Am Coll Cardiol 1999;33:1136-40.

33. Castelli WP, Garrison RJ, Wilson PW, Abbott RD, Kalousdian S, Kannel WB. Incidence of coronary heart disease and lipoprotein cholesterol levels. The Framingham Study. JAMA 1986;256:2835-8

34. Grover SA, Palmer CS, Coupal L. Serum lipid screening to identify high-risk individuals for coronary death. The results of the Lipid Research Clinics prevalence cohort. Arch Intern Med 1994;154:679-84

35. Assmann G, Cullen P, Schulte H. The Munster Heart Study (PROCAM). Results of follow-up at 8 years. Eur Heart J 1998;19 Suppl:A2-11.

36. Romm PA, Green CE, Reagan K, Rackley CE. Relation of serum lipoprotein cholesterol levels to presence and severity of angiographic coronary artery disease. Am J Cardiol 1991;67:479-83.

37. Hong MK, Romm PA, Reagan K, Green CE, Rackley CE. Usefulness of the total cholesterol to high-density lipoprotein cholesterol ratio in predicting angiographic coronary artery disease in women. Am J Cardiol 1991;68:1646-50.

38. Ridker PM, Hennekens CH, Buring JE, Rifai N. C-reactive protein and other markers of inflammation in the prediction of cardiovascular disease in women. N Engl J Med 2000;342:836-43.

39. Lewington $\mathrm{S}$, Whitlock $\mathrm{G}$, Clarke R, et al. Blood cholesterol and vascular mortality by age, sex, and blood pressure: a meta-analysis of individual data from 61 prospective studies with 55,000 vascular deaths. Lancet 2007;370:1829-39.

40. Castelli WP. The new pathophysiology of coronary artery disease. Am J Cardiol 1998;82:60T-5T

41. Georgiadis AN, Papavasiliou EC, Lourida ES, et al. Atherogenic lipid profile is a feature characteristic of patients with early rheumatoid arthritis: effect of early treatment - a prospective, controlled study. Arthritis Res Ther 2006;8:R82.

42. Sari RA, Polat MF, Taysi S, Bakan E, Capoglu I. Serum lipoprotein(a) level and its clinical significance in patients with systemic lupus erythematosus. Clin Rheumatol 2002;21:520-4.

43. Siripaitoon B, Osiri M, Vongthavaravat V, Akkasilpa S, Personal non-commercial use only. The Journal of Rheumatology Copyright @ $@ 2009$. All rights reserved. 
Deesomchok U. The prevalence of dyslipoproteinemia in Thai patients with systemic lupus erythematosus. Lupus 2004;13:961-8.

44. Formiga F, Meco JF, Pinto X, Jacob J, Moga I, Pujol R. Lipid and lipoprotein levels in premenopausal systemic lupus erythematosus patients. Lupus 2001;10:359-63.

45. Kiss E, Fazekas B, Tarr T, Muszbek L, Zeher M, Szegedi G. Lipid profile in patients with systemic lupus erythematosus, with special focus on lipoprotein(a) in lupus nephritis. Orv Hetil 2004; 145:217-22.

46. Attman PO, Alaupovic P. Lipid abnormalities in chronic renal insufficiency. Kidney Int Suppl 1991;31:S16-23.

47. Petri M, Lakatta C, Magder L, Goldman D. Effect of prednisone and hydroxychloroquine on coronary artery disease risk factors in systemic lupus erythematosus: a longitudinal data analysis. Am J Med 1994;96:254-9.

48. Bruce IN, Urowitz MB, Gladman DD, Hallett DC. Natural history of hypercholesterolemia in systemic lupus erythematosus. J Rheumatol 1999;26:2137-43.

49. MacGregor AJ, Dhillon VB, Binder A, et al. Fasting lipids and anticardiolipin antibodies as risk factors for vascular disease in systemic lupus erythematosus. Ann Rheum Dis 1992;51:152-5.

50. Rahman P, Gladman DD, Urowitz MB, Yuen K, Hallett D, Bruce IN. The cholesterol lowering effect of antimalarial drugs is enhanced in patients with lupus taking corticosteroid drugs. J Rheumatol 1999;26:325-30. 